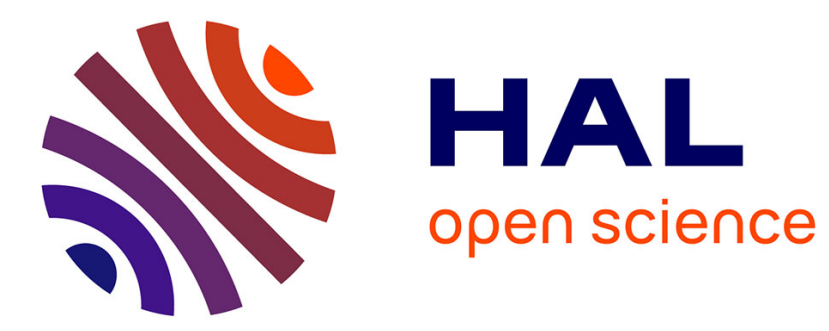

\title{
La/B4C small period multilayer interferential mirrors for the analysis of boron
}

J.-M André, Philippe Jonnard, C Michaelsen, J Wiesmann, F Bridou, M.-F Ravet, A Jérome, Franck Delmotte, E. O. Filatova

\section{- To cite this version:}

J.-M André, Philippe Jonnard, C Michaelsen, J Wiesmann, F Bridou, et al.. La/B4C small period multilayer interferential mirrors for the analysis of boron. X-Ray Spectrometry, 2004, 34 (3), pp.203206. 10.1002/xrs.793 . hal-01232846

\section{HAL Id: hal-01232846 \\ https://hal.science/hal-01232846}

Submitted on 24 Nov 2015

HAL is a multi-disciplinary open access archive for the deposit and dissemination of scientific research documents, whether they are published or not. The documents may come from teaching and research institutions in France or abroad, or from public or private research centers.
L'archive ouverte pluridisciplinaire HAL, est destinée au dépôt et à la diffusion de documents scientifiques de niveau recherche, publiés ou non, émanant des établissements d'enseignement et de recherche français ou étrangers, des laboratoires publics ou privés. 


\title{
$\mathrm{La} / \mathrm{B}_{4} \mathrm{C}$ small period multilayer interferential mirrors for the analysis of boron
}

J.-M. André*, P. Jonnard

Laboratoire de Chimie Physique-Matière et Rayonnement, Université Pierre et Marie Curie LCP-MR , UMR-CNRS 7614, 11 rue Pierre et Marie Curie, 75231 Paris Cedex 05, France

C. Michaelsen, J. Wiesmann

Incoatec GmbH, Max-Planck-Strasse 2, 21502 Geesthacht, Germany

F. Bridou, M.-F. Ravet, A. Jérome, F. Delmotte

Groupe de Physique des Films Minces, Laboratoire Charles Fabry de l'Institut d'Optique, UMR-CNRS 8501, Centre Scientifique, Bât. 503, 91403 Orsay Cedex, France.

E. O. Filatova

Institute of Physics, St Petersburg University, Ulianovskaya 1, St Petersburg, 198904 Russia

*corresponding author: andrejm@,ccr.jussieu.fr

\begin{abstract}
A La/ $\mathrm{B}_{4} \mathrm{C}$ multilayer interferential mirror with small period $\mathrm{d}(4.8 \mathrm{~nm})$ was produced by diode sputtering for the detection of the boron $\mathrm{K}$ emission by wavelength-dispersive $\mathrm{X}$-ray spectrometry at a large Bragg angle (close to $45^{\circ}$ ). The structure of the mirror has been characterized by grazing incidence x-ray reflectometry, and its performance at the energy of the boron $\mathrm{K}$ emission $(183 \mathrm{eV})$ was evaluated by means of polarized synchrotron radiation. A spectrometric measurement shows that the $\mathrm{La} / \mathrm{B}_{4} \mathrm{C}$ mirror has improved the detection limit of boron using by a factor of 2 with respect to similar Mo/B $\mathrm{B}_{4} \mathrm{C}$ mirrors, and by a factor of 4 with respect to a lead stearate crystal.
\end{abstract}




\section{INTRODUCTION}

The analysis of the boron emission by Wavelength Dispersive X-Ray Fluorescence (WDXRF) or Electron Probe MicroAnalysis (Castaing microprobe, or EPMA) is of considerable importance in semiconductor, ceramic and glass industries, and also for geological investigations. Until the advent of multilayer analyzers, lead stearate (LS) soap films, made up by the Langmuir-Blodgett technique, were extensively used to analyze the B$\mathrm{K}$ emission. Since the nineties, $\mathrm{Mo} / \mathrm{B}_{4} \mathrm{C}$ multilayer interferential mirrors (MIMs) are commercially available. They had progressively taken the place of the soap films for the analysis of boron emission since they offer a larger integrated reflectivity [1].

Recently it has been pointed out that $\mathrm{La} / \mathrm{B}_{4} \mathrm{C}$ MIMs can be advantageously implemented for the detection of boron emission by WDXRF. Basically, this fact comes from the small absorption of lanthanum in the energy range of the boron $\mathrm{K}$ emission, compared to that of molybdenum or tungsten. The $\mathrm{La} / \mathrm{B}_{4} \mathrm{C}$ MIMs improve the detection limit of $\mathrm{B}$ in silicon wafer by about $28 \%$ with respect to conventional $\mathrm{Mo} / \mathrm{B}_{4} \mathrm{C}$ MIMs [2]. In this paper we present an extended characterization of a small period La/ $\mathrm{B}_{4} \mathrm{C}$ MIM $(\mathrm{d}=4.8 \mathrm{~nm})$, both by hard x-ray grazing incidence reflectometry and soft x-ray reflectometry using polarized synchrotron radiation. The performance of $\mathrm{La} / \mathrm{B}_{4} \mathrm{C}$ MIMs with larger periods has been investigated in a previous work [3]. Decreasing the period allows to increase the Bragg angle and consequently to improve the spectral dispersion. Moreover the period that we have chosen leads to a Bragg angle close to $45^{\circ}$ at $183 \mathrm{eV}$, which gives the MIM the quality of a polarizer, since the TM component of the electric field is cancelled by the reflection. Unfortunately diminishing the thickness of the layers in a MIM leads generally to a decrease in its performance for various reasons : the influence of the interfacial layers on the reflectivity caused by interdiffusion process, chemical reactions and implantation during the sputtering process is increased. Moreover the correlation between the substrate and film roughness can become very important for MIMs with short period.

The purpose of this paper is to give the state-of-the-art in the soft x-ray reflectivity performances of small period $\mathrm{La} / \mathrm{B}_{4} \mathrm{C}$ MIMs. They are characterized by Grazing Incidence Xray Reflectometry (GIXR) at $0.154 \mathrm{~nm}$. The advantageous performance of this new La/B4C $\mathrm{MIM}$ in the case of boron is shown by comparing it to the one of a similar Mo/ ${ }_{4} \mathrm{C}$ MIM and of a LS film, in a typical spectroscopic application. 


\section{MIRROR FABRICATION}

Four $\mathrm{La} / \mathrm{B}_{4} \mathrm{C}$ multilayers were produced in the same batch, leading to identical parameters. They were deposited onto Si wafers one inch in diameter, by conventional diode magnetron sputtering in a vacuum system with a base pressure in the $10^{-6} \mathrm{~Pa}$ range [4]. Ar of purity 6.0 at a pressure of typically $0.1 \mathrm{~Pa}$ was used as the sputtering ambient. The substrate holder was water-cooled. The deposition times were controlled by a computer-driven shutter located between the sample and the targets. Typical deposition rates were in the order of $0.1 \mathrm{~nm} / \mathrm{s}$. After deposition, the film thickness and the ratio of the La layer thickness to the period (gamma ratio) were determined at various positions along the mirror surface by $\mathrm{x}$-ray reflectometry using a Bruker AXS D8 Advance diffractometer.

At the same time, two $\mathrm{Mo} / \mathrm{B}_{4} \mathrm{C}$ multilayers with a similar period were fabricated by ion beam sputtering in a ultra-high vacuum chamber [5] using an ION TECH Inc. $3 \mathrm{~cm}$ ion beam source with a hollow cathode, a hollow cathode neutralizer, and a three position target holder. A base pressure in the $10^{-7} \mathrm{~Pa}$ range is reached by using a cryopump and by baking out the chamber during around 6 hours, then by filling a cold trap with liquid nitrogen. A mixture of $10 \% \mathrm{H}_{2}$ in Ar gas is injected into the ion gun and pure argon is injected into the neutralizer. The 5 inches diameter molybdenum and silicon targets are successively sputtered by rotating the target holder system. Multilayers were deposited in this case on float glass substrates with a $20 \mathrm{~mm}$ diameter and a $3 \mathrm{~mm}$ thickness. The layer thickness is roughly controlled during the deposition by using an in-situ reflectometer working at $0.154 \mathrm{~nm}$.

\section{CHARACTERIZATION}

Grazing incidence x-ray reflectometry at the $0.154 \mathrm{~nm}$ wavelength $(\mathrm{Cu} \mathrm{K \alpha}$ emission), together with appropriate software, is a well-mastered and efficient technique to determine the characteristics of MIMs. It gives the layer thickness in-depth distribution of the stack and the interfacial roughness parameters [6].

The GIXR has been applied to characterize the $\mathrm{La} / \mathrm{B}_{4} \mathrm{C}$ and $\mathrm{Mo} / \mathrm{B}_{4} \mathrm{C}$ MIMs. Table 1 and 2 give the parameters obtained for the MIMs. One notes that the value of the root mean square (rms) roughness $\sigma$ depends on the order of deposition, a fact which is well-known in multilayer physics. The La decrement of the optical index is equal to the theoretical one multiplied by a factor of 0.81 . That value corresponds to $81 \%$ of the bulk density. The 
uncertainty on the period is about $0.1 \mathrm{~nm}$, while the thickness of each layer in this period is defined in a precision range of about $0.2 \mathrm{~nm}$.

\section{ABSOLUTE REFLECTIVITY AT $183 \mathrm{eV}$}

The absolute reflectivity at the energy of the B-K emission $(183 \mathrm{eV})$, has been measured by means of the polarimeter set-up [7] at the UE56/1-PGM beamline of the BESSY II synchrotron facility. The beamline is equipped with an undulator and a $1200 \mathrm{l} / \mathrm{mm}$ plane grating monochromator. The spectral bandwidth of the monochromatic radiation is less than $20 \mathrm{meV}$ at $183 \mathrm{eV}$ for the width of the exit slit chosen in our measurements. The polarization of the radiation can be adjusted by varying the configuration of the undulator.

Figure 1 displays the experimental reflectivity versus glancing angle at $183 \mathrm{eV}$ for circularly polarized radiation. The experimental results are adjusted by using the data of the GIXR measurements as starting values is given in Figure 1. The fit implements the matrix formalism with the transition layer model to calculate the reflectivity in presence of interfacial roughness [8]. We have chosen to determine the parameters of the MIM from the reflectivity measurement at fixed energy, because in this case, the fitting process is not affected by the badly known variations of the optical constants (dispersion) as a function of the energy. In the inset of the Figure 1,we have noted the values of the thickness retained to obtain an « exact » fit ; these values lie in the domain of confidence of the GIXR measurements. In the inset we also give the value of the global Debye-Waller factor, $\sigma=0.3 \mathrm{~nm}$, needed to take into account the interfacial roughness effect in the Debye-Waller model. One notes that this value is slightly smaller than the rms values estimated by a more sophisticated model that takes into account independently the effects of each interfacial roughness [6]. The slight difference in the d-spacings observed by hard and by soft x-rays may be due to a limited knowledge of the optical constants for the materials used.

Figures 2 and 3 show the experimental reflectivity versus photon energy for the circularly polarized and TE (s) radiation respectively, at a glancing angle of $45^{\circ}$, together with the fit obtained using the parameters (thicknesses, roughnesses and densities) of the above "exact" fit. The TM (p) reflection is practically cancelled as expected because the glancing angle is very close to the Brewster angle. The agreement between experimental results and fit is good, indicating that the theoretical reflection curves calculated using the parameters from the GIXR measurements are in close agreement with the soft $\mathrm{x}$-ray experiments.

We have performed the same calculations for Mo instead of La, keeping the other parameters fixed. The peak reflectivity for TE polarization that reached $42.8 \%$ with $\mathrm{La}$ as absorbing layer, is only $21.2 \%$ with Mo as absorbing layer, and the peak reflectivity for circular polarization which is $21.4 \%$ for La drops to $10.6 \%$ for Mo. No significant change of 
the spectral bandwidth occurs by substituting La for Mo. These results show, both theoretically and experimentally, that the $\mathrm{La} / \mathrm{B}_{4} \mathrm{C}$ structure is more efficient than the $\mathrm{Mo} / \mathrm{B}_{4} \mathrm{C}$ structure for spectroscopic applications at $183 \mathrm{eV}$.

\section{SPECTROSCOPIC APPLICATIONS}

The $\mathrm{La} / \mathrm{B}_{4} \mathrm{C}$ and $\mathrm{Mo} / \mathrm{B}_{4} \mathrm{C}$ MIMs and the LS crystal have been used to analyze the $\mathrm{B}-\mathrm{K}$ emission from the same hexagonal $\mathrm{BN}$ bulk sample in the same electron excitation conditions $(10 \mathrm{~mA}, 3 \mathrm{kV})$. The measurements were carried out by means of the original spectrogoniometer MONOX [9]. Figure 4 gives a comparison of the relative intensities of the B-K emission obtained with the three analyzers. It is seen from this figure that the reflectivity of the $\mathrm{La} / \mathrm{B}_{4} \mathrm{C}$ MIM is twice as that of the Mo/B ${ }_{4} \mathrm{C}$ MIM, and about ten times that of the LS crystal. These results confirm the low efficiency of the LS crystal and the superiority of $\mathrm{La} / \mathrm{B}_{4} \mathrm{C}$ MIM with respect to the $\mathrm{Mo} / \mathrm{B}_{4} \mathrm{C} \mathrm{MIM}$ in terms of peak reflectivity.

We have calculated the detection limit of boron, $\mathrm{C}_{\mathrm{lim}}$, for each analyzer. It can be defined in a 3 standard deviations of the confidence interval by :

$$
\mathrm{C}_{\lim }=3 \mathrm{~b}^{1 / 2} \mathrm{p}^{-1} \mathrm{C} \text {, }
$$

where $\mathrm{b}$ and $\mathrm{p}$ are the number of counts of the background and the peak, respectively, and $\mathrm{C}$ the concentration of boron atoms in the BN sample. The detection limit calculated for the present experimental conditions $(3 \mathrm{keV}, 10 \mathrm{~mA}, 10 \mathrm{~s})$ are presented in Table 3 . The detection limit improves by a factor of 2 going from $\mathrm{LS}$ to $\mathrm{Mo} / \mathrm{B}_{4} \mathrm{C}$, and by another factor of 2 from $\mathrm{Mo} / \mathrm{B}_{4} \mathrm{C}$ to $\mathrm{La} / \mathrm{B}_{4} \mathrm{C}$. These detection limits can be improved still further by increasing the acquisition time or the electron current. Nevertheless the detection of boron traces by MIMs containing boron in their composition remains problematic because of the anomalous reflection. Let us recall that in the vicinity of an absorption egde of an element constituting an $\mathrm{x}$-ray reflector (here boron in a $\mathrm{La} / \mathrm{B}_{4} \mathrm{C}$ multilayer mirror), $\mathrm{x}$-ray anomalous scattering by this element occurs, giving rise to troublesome structures in the reflection $[10,11]$.

\section{CONCLUSION}

$\mathrm{La} / \mathrm{B}_{4} \mathrm{C}$ MIMs with small period for WDXRF detection of boron at a Bragg angle of $45^{\circ}$ have been produced and successfully tested. They offer performances similar to larger period $\mathrm{La} / \mathrm{B}_{4} \mathrm{C}$ MIMs developed to detect boron at a lower Bragg angle [3]. The boron detection limit of these MIMs is a factor 2 better compared to $\mathrm{Mo} / \mathrm{B}_{4} \mathrm{C}$ MIMs.

Moreover, the possibility to diffract efficiently photons of $183 \mathrm{eV}$ at $45^{\circ}$, that is close to the Brewster angle, should make these MIMs useful as polarizers, and the development of luminous spectroscopic devices, such as the one recently developed by S. Ishikawa et al. [12] for the study of anisotropic boron compounds. 


\section{Acknowledgements}

This work has been partly carried out at BESSY II in the framework of the project BESSY-Number HPP33/150902 and supported by the European Commission under the "Human Potential Programme, Transnational Access to Major Research Infrastructures", Contract No HPRI-1999-00028. The authors thank H.-C. Mertins and D. Abramsohn for their help during the measurements at BESSY II. 


\section{References}

1. McGee J. J., Slack J. F. and Herrington C. R. Am. Mineral. 1991; 76: 681-684.

2. Ricardo P., Wiesmann J., Nowak C., Michaelsen C. and Bormann R. Appl. Opt. 2001; 40: $2747-2754$.

3. Michaelsen C., Wiesmann J. and Bormann R. Opt. Lett. 2001; 26: 792-794.

4. Michaelsen C., Ricardo P., Anders D., Schuster M., Schilling J. and Göbel H. Adv. XRay Anal. 2000; 42: 308-320.

5. Ravet M.-F., Bridou F., Zhang-Song X., Jérome A., Delmotte F., Mercier R., Bougnet M., Bouyries P. and Delaboudiniere J.-P. Proc.SPIE 2003; 5250: 12-18.

6. Bridou F. and Pardo B , J. Optics (Paris) 1990; 21: 183-191.

7. Schäfers F. et al. Appl. Opt. 1999; 38: 4074-4088.

8. Pardo B., Megademini T. and André J.-M. Rev. Phys. Appl. 1988; 23: 1579-1597.

9. J.-M. André et al., to appear in J. Phys. IV France; http://www.ccr.jussieu.fr/lcpmr/.

10. Marmoret R. and André J.-M. Appl. Opt. 1983; 22: 17-19.

11. Hombourger C., Jonnard P., André J.-M. and Chauvineau J.-P. X-Ray Spectrom. 1999; 28:163-167.

12. Ishikawa S. et al. Opt. Rev. 2003; 10 : 58-62. 
Table 1 : Parameters of the $\mathrm{La} / \mathrm{B}_{4} \mathrm{C}$ MIM deduced from GIXR measurements at $0.154 \mathrm{~nm}$. $\mathrm{N}^{\circ}$ is the number of the layer within the stack. "Absorption" means the imaginary part of the optical index.

\begin{tabular}{|lc|c|c|c|c|}
\hline Layer & $\left(\mathrm{N}^{\circ}\right)$ & Thickness $(\mathrm{nm})$ & Roughness $(\mathrm{nm})$ & $\begin{array}{c}\text { Refractive index } \\
(1-\mathrm{n}) \times 10^{6}\end{array}$ & $\begin{array}{c}\text { Absorption } \\
\mathrm{x}^{6} 0^{6}\end{array}$ \\
\hline Substrate & 0 & $\infty$ & 0.48 & 7.7 & 0.13 \\
\hline La & 1 & 2.3 & 0.59 & 12.8 & 1.7 \\
\hline $\mathrm{B}_{4} \mathrm{C}$ & 2 & 2.5 & 0.44 & 6.84 & 0.71 \\
\hline$\ldots$ & & & & & \\
\hline $\mathrm{B}_{4} \mathrm{C}$ & 140 & 6.2 & 0.86 & 7.12 & 0.71 \\
\hline
\end{tabular}

Table 2 : Parameters of the $\mathrm{Mo} / \mathrm{B}_{4} \mathrm{C}$ MIM deduced from GIXR measurements at $0.154 \mathrm{~nm}$. $\mathrm{N}^{\circ}$ is the number of the layer within the stack. "Absorption" means the imaginary part of the optical index.

\begin{tabular}{|lc|c|c|c|c|}
\hline Layer & $\left(\mathrm{N}^{\circ}\right)$ & Thickness $(\mathrm{nm})$ & Roughness $(\mathrm{nm})$ & $\begin{array}{c}\text { Refractive index } \\
(1-\mathrm{n}) \times 10^{6}\end{array}$ & $\begin{array}{c}\text { Absorption } \\
\mathrm{x} 10^{6}\end{array}$ \\
\hline Substrate & 0 & $\infty$ & 0.44 & 7.7 & 0.13 \\
\hline $\mathrm{Mo}$ & 1 & 2.5 & 0.45 & 24.93 & 1.6 \\
\hline $\mathrm{B}_{4} \mathrm{C}$ & 2 & 2.4 & 0.26 & 6.46 & 0.71 \\
\hline$\ldots$ & & & & & \\
\hline $\mathrm{B}_{4} \mathrm{C}$ & 166 & 2.4 & 0.49 & 6.46 & 0.71 \\
\hline
\end{tabular}

\section{Table 3}

Detection limit for the boron atoms with the three studied analyzers.

\begin{tabular}{|c|c|}
\hline Analyzer & $\begin{array}{c}\text { Detection limit } \\
\left(10^{20} \text { at.cm }{ }^{-3}\right)\end{array}$ \\
\hline $\mathrm{La} / \mathrm{B}_{4} \mathrm{C}$ & 4.9 \\
\hline $\mathrm{Mo} / \mathrm{B}_{4} \mathrm{C}$ & 10.7 \\
\hline Lead stearate & 18.8 \\
\hline
\end{tabular}




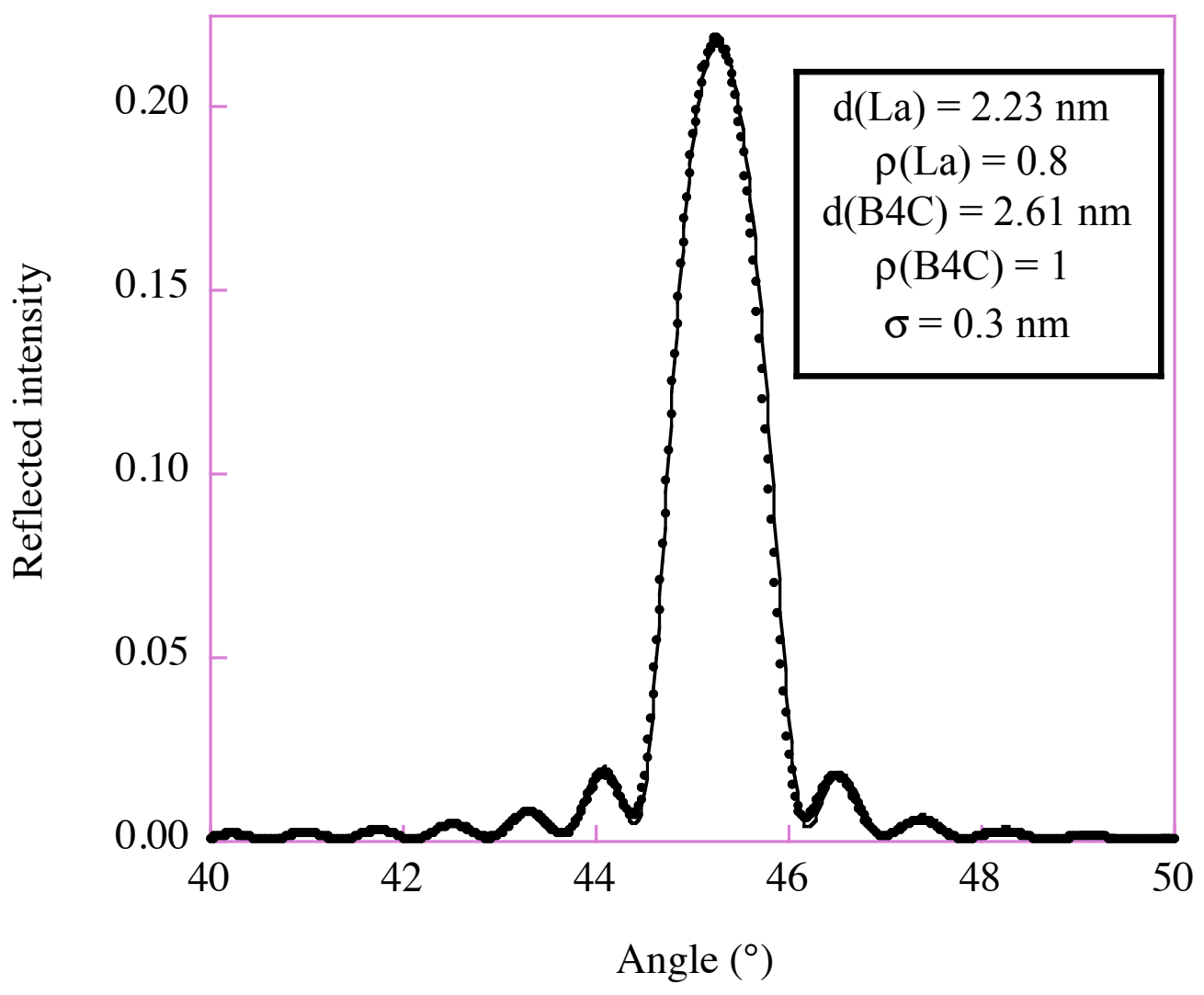

Figure 1 : Experimental (dots) and theoretical (line) reflectivity versus glancing angle at $183 \mathrm{eV}$ for circularly polarized radiation. The theoretical reflectivity curve is a fit using the results of the GIXR measurements as starting values. In the inset we have noted the values used to obtain an «exact» fit: $\mathrm{d}(\mathrm{La})$ and $\mathrm{d}(\mathrm{B} 4 \mathrm{C})$ are the thicknesses of the $\mathrm{La}$ and $\mathrm{B}_{4} \mathrm{C}$ layers, respectively, $\rho(\mathrm{La})$ and $\rho(\mathrm{B} 4 \mathrm{C})$ are the densities relative to those of the bulk materials, respectively, and $\sigma$ is the Debye-Waller roughness. 


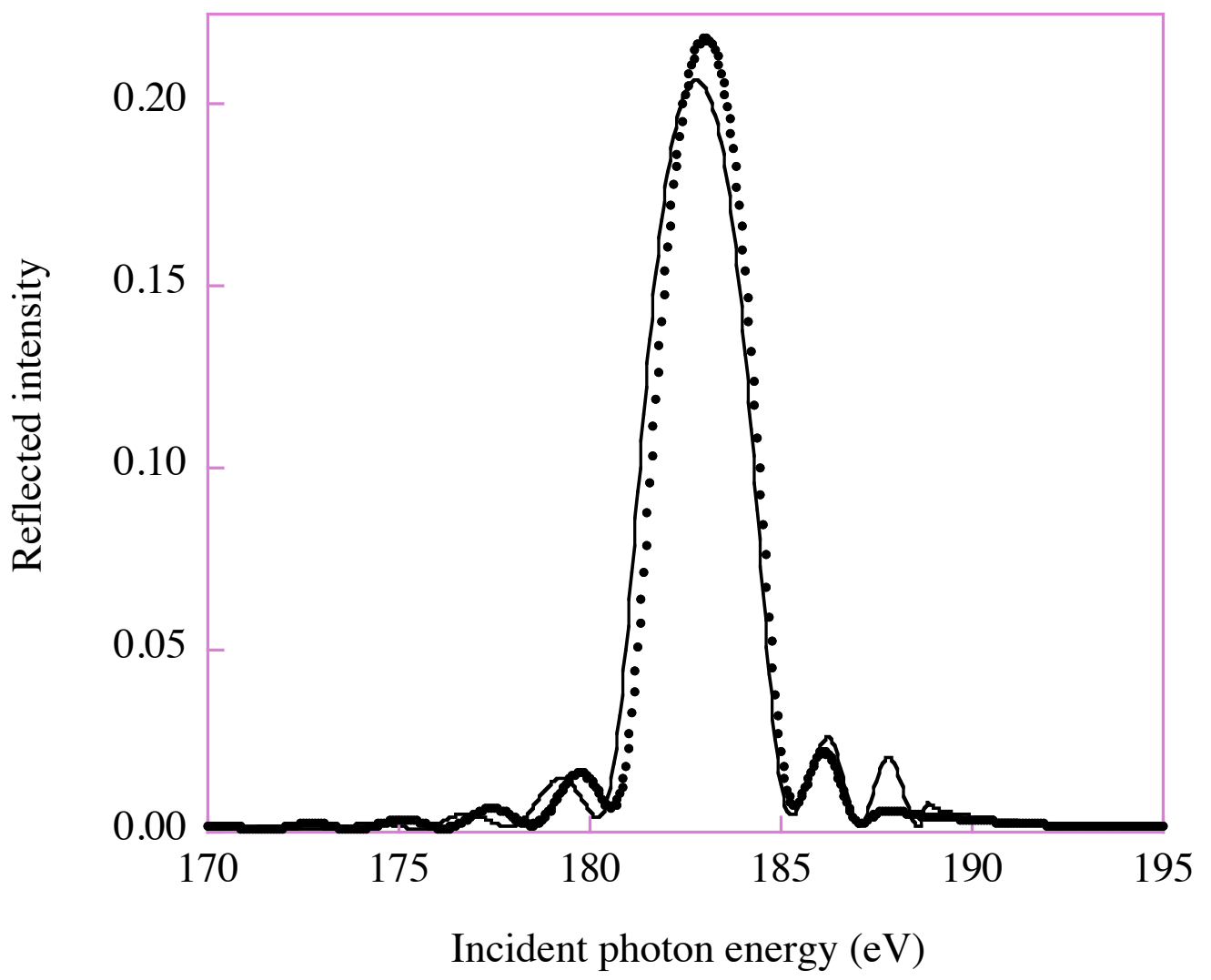

Figure 2 : Experimental reflectivity (dots) versus energy at a $45^{\circ}$ glancing angle for circularly polarized radiation. « Theory » (line) is the reflectivity calculated with the same parameters as in Fig. 1. 


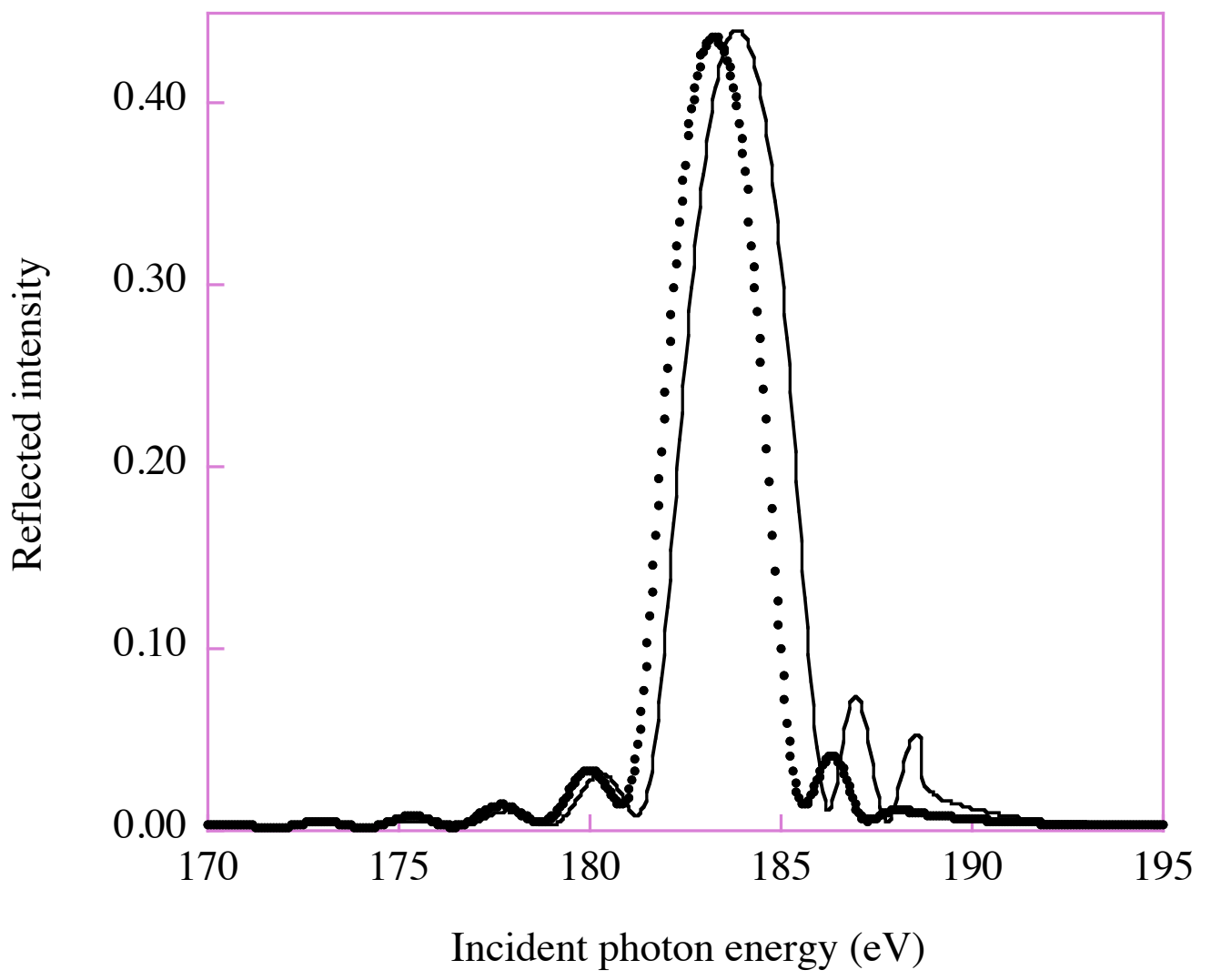

Figure 3: Experimental reflectivity (dots) versus energy at a $45^{\circ}$ glancing angle for TE polarization of the radiation. «Theory » (line) is the reflectivity calculated with with the same parameters as in Fig. 1. 


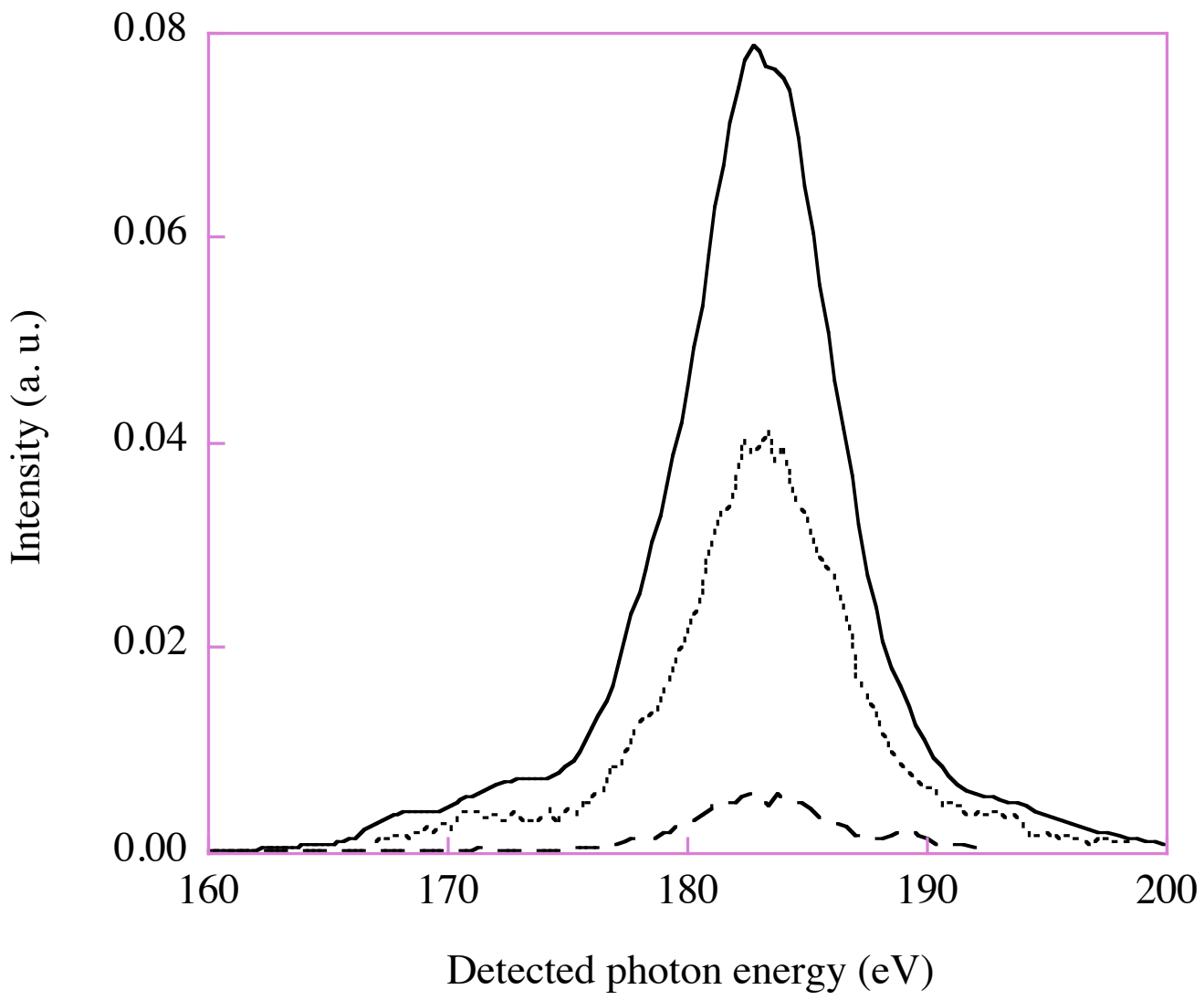

Figure 4 : Comparison of the B-K emission spectrum from a $\mathrm{BN}$ sample recorded with the $\mathrm{La} / \mathrm{B}_{4} \mathrm{C}$ (solid line) and $\mathrm{Mo} / \mathrm{B}_{4} \mathrm{C}$ (dotted line) MIMs and the LS crystal (dashed line). 